\title{
PELES HABITÁVEIS DE ALMODÓVAR EM PERSPECTIVA: PROJEÇÕES (META)ESCALARES
}

\author{
Almodóvar's Livable Skins in Perspective: Pieles Habitables de Almodóvar en \\ (Meta)Scalar Projections Perspectiva: Proyecciones (Meta)Escalares
}

\author{
Clarissa Gonzalez* \\ Luiz Paulo da Moita Lopes** \\ Universidade Federal do Rio de Janeiro \\ Centro de Letras e Artes da Faculdade de Letras \\ Rio de Janeiro, RJ, Brasil
}

\begin{abstract}
Resumo: Tendo como referência uma perspectiva performativa de linguagem (AUSTIN, 1962/1990), este artigo analisa uma videocrítica publicada no Youtube sobre o filme A pele que habito com o objetivo de identificar com que discursos orientadores seu autor se alinha, especialmente no que tange ao gênero. Recorre a teorizações queer para efetuar o embasamento teórico. A análise, um exercício metaescalarreflexivo, abarca, além das noções de escalas (CARR; LEMPERT, 2016) e de indexicalidade (SILVERSTEIN, 2003), outros construtos teórico-analíticos: iconização, apagamento e recursividade fractal (IRVINE; GAL, 2000; GAL, 2016). Busca, assim, sinalizar como a obra de Almodóvar é perspectivizada e as estratégias semióticas que remetem a determinadas ideologias. O que se observa é que significados em disputa se entrelaçam no discurso do youtuber, que, apesar de falar de construção de gênero, fundamenta seu ponto de vista usando uma metalinguagem que evoca noções essencialistas e deterministas, indo de encontro àquelas mobilizadas no filme.
\end{abstract}

Palavras-chave: Escalas. Indexicalidade. Processos semióticos.

\begin{abstract}
Oriented by a performative perspective of language (AUSTIN, 1962/1990), in this article we analyze a video-critique published on YouTube on the movie The skin I live in order to identify with which guiding discourses its author is aligned, especially regarding the gender. Our theoretical approach focuses on queer theories. The analysis, a metascalar-reflexive exercise, is based on the notions of scales (CARR; LEMPERT, 2016) and indexicality (SILVERSTEIN, 2003), making complementary use of other theoretical-analytical constructs: iconization, erasure and fractal recursivity (IRVINE; GAL, 2000; GAL, 2016). We also aim to point how Almodóvar's film is perspectivized and the semiotic strategies that refer to certain ideologies. What we observe is there are conflicting meanings that intertwine in the discourse of the youtuber, who despite speaking of gender construction builds up his point of view up using a metalanguage that evokes essentialist and deterministic notions, which go against those mobilized in the film.
\end{abstract}

Keywords: Scales. Indexicality. Semiotic processes.

\footnotetext{
* Pesquisadora PNPD (CAPES) do Programa de Pós-Graduação Interdisciplinar em Linguística Aplicada da UFRJ. ORCID: <https://orcid.org/0000-0002-3521-897X>. E-mail: gonzalezclariss@gmail.com.

** Professor Titular aposentado do Programa de Pós-Graduação Interdisciplinar em Linguística Aplicada da UFRJ. Pesquisador de Produtividade em Pesquisa (CNPq 302935/2017-7). ORCID: $<$ https://orcid.org/0000-0002-3829-9824>. E-mail: moitalopes@pq.cnpq.br.
} 
Resumen: Teniendo como referencia una perspectiva performativa de lenguaje (AUSTIN, 1962/1990), este artículo analiza una video crítica publicada en Youtube sobre la película La piel que habito, con el objetivo de identificar con cuáles discursos guiadores su autor se alinea, especialmente en lo que se refiere a género. Recurre a teorizaciones queer para efectuar su basamento teórico. El análisis, un ejercicio meta escalar-reflexivo, abraza, además de las nociones de escalas (CARR; LEMPERT, 2016) y de indexicalidad (SILVERSTEIN, 2003), otros constructos teórico-analíticos: iconización, apagamiento y recursividad fractal (IRVINE; GAL, 2000; GAL, 2016). Busca, así, señalar cómo la obra de Almodóvar es perspectivizada y las estrategias semióticas que remeten para determinadas ideologías. Lo que se observa es que significados en disputa se entrelazan en el discurso del youtuber que, a pesar de hablar de construcción de género, basa su punto de vista usando un metalenguaje que evoca nociones esencialistas y deterministas, indo en contra aquellas movilizadas en la película.

Palabras clave: Escalas. Indexicalidad. Procesos semióticos.

O mais profundo é a pele

(Paul Valéry ${ }^{1}$ )

\section{PERCEPÇÕES INTRODUTÓRIAS}

Por mais que seja composta de diferentes camadas (epiderme, derme e hipoderme) e tenha múltiplas funções (proteção, termorregulação, excreção, captação de estímulos dolorosos e táteis), a acepção mais usual de pele é a indicada pela segunda entrada do verbete no dicionário Michaelis": "camada mais externa e superficial” que reveste o corpo.

Em 'A pele que habito', o cineasta Pedro Almodóvar parece contrariar esta acepção. O filme adentra às profundezas da pele: é em torno da pele que todo o enredo se estrutura. Este gira ao redor de três pontos: a destruição da pele (carbonização como consequência de um acidente de carro), a obsessão que inspira (criação de uma pele resistente a qualquer tipo de dano) e a transformação que viabiliza (redesignação de gênero). No filme, a pele adquire papel protagônico e chega a adquirir nome próprio.

Gal é o nome que o Dr. Robert, personagem crucial do filme, dá a pele que cria. Como aponta o youtuber Gabriel Tosto na vídeo-crítica ${ }^{3}$ a ser analisada, o nome alude à Galetea, estátua que Pigmaleão, no mito grego, esculpe e pela qual se apaixona. Esta analogia propiciada pelo ato de nomear, performativamente, produz efeitos: a pele, ao ser nomeada Gal, além de ser humanizada, cumpre, de forma diferenciada (já que, em meio à repetição, há alteração de significado [DERRIDA, 1972/1991]), sua vocação mitológica.

$\mathrm{O}$ ato de nomear, na referida obra cinematográfica, ganha extrema relevância: os nomes dos personagens, por exemplo, tal como a pele nomeada Gal, além da transposição metafórica para a qual apontam, perspectivizam as questões que enunciam. Enfoquemos brevemente três deles: Vera, Vicente e Norma. O nome 'Vera' está relacionado com a ideia de verdade/veracidade. É dessa forma que Almodóvar, por meio do doutor Robert, batiza a criatura a qual dá forma. O médico atribui esta alcunha a Vicente depois de

\footnotetext{
${ }^{1}$ Deleuze (1969/1975, p. 11) destaca a importância de olhar para efeitos de superfície citando Valéry.

${ }^{2}$ Disponível em: https://michaelis.uol.com.br/moderno-portugues/busca/portugues-brasileiro/pele/. Acesso em 28 jul. 2018.

${ }^{3}$ É a crítica, ou seja, análise avaliativa, registrada em vídeo.
} 
submetê-lo a um processo de redesignação de gênero forçado. Tal escolha poderia sinalizar que o cineasta, por meio de Vera, questionaria o que se entende por verdade, mostrando que esta pode ter diferentes dimensões. $\mathrm{O}$ filme parece indicar que a verdade, assim como Vera, é produto de uma construção, sendo, portanto, "desse mundo" (FOUCAULT, 1972/1984). Já o nome 'Vicente', originado do latim 'Vincentius', deriva de 'vincente', particípio passado do verbo 'vincere', que significa "vencer"4. E Vicente, em grande medida, sai vencedor de uma situação improvável: logra fugir de seu algoz performando estrategicamente feminilidade. $\mathrm{O}$ filme, desse modo, adverte que o gênero é performado (BUTLER, 1990/2007). O item lexical 'norma', por sua vez, aponta para convenções/resoluções/padrões a serem seguidos. Norma, marcada pelo trauma de ter presenciado o suicídio da mãe, mostra-se débil e sobre ela recaem vários estereótipos que, muitas vezes, pesam sobre as 'mulheres': é frágil, infantilizada, instável e histérica. Por ser considerada incapaz de assumir as rédeas da própria vida, vive sob a tutela de um homem. Diante da impossibilidade de produzir diferença em meio à repetição, não foge à regra: cumpre o mesmo destino trágico de sua mãe. Todas estas questões, além de referendarem a importância do ato de nomear, são atravessadas por debates que envolvem performances de gênero, tema central da vídeo-crítica a ser analisada.

Esta escolha (análise de uma vídeo-crítica cinematográfica produzida por um usuário do Youtube) mostra-se em sintonia com novos modos de se 'prosumir' (TOFFLER, 1980) diferentes tipos de textos ${ }^{5}$ em circulação, sejam estes sonoros, verbais, imagéticos ou audiovisuais.

O termo 'prosumidor', tradução nossa do inglês 'prosumer', acrônimo resultante da junção das palavras 'producer'(produtor) e 'consumer' (consumidor), foi cunhado por Toffler (1980) para destacar o modo como a produção e o consumo de conteúdos mesclam-se cada vez mais nas mídias sociais. Críticas produzidas por usuários de redes sociais sobre artefatos culturais, como o cinema, ilustram bem o fenômeno referenciado por Toffler. Estes usuários, além de consumirem as obras em questão, produzem conteúdos sobre elas. Um destes conteúdos (a vídeo-crítica realizada pelo youtuber Gabriel Tosto sobre o filme 'A pele que habito'), fruto de projeções (meta)escalares, ou seja, de um exercício duplamente reflexivo (é a reflexão sobre uma obra cinematográfica, a qual, por sua vez, resulta de um exercício reflexivo efetuado pelo cineasta que a dirigiu), é o objeto sobre o qual nos debruçamos na pesquisa.

De caráter qualitativo-interpretativista, nosso estudo não tem a pretensão de tecer generalizações ou projetar verdades, uma vez que entendemos que a produção de conhecimento é sempre situada, parcial, interessada (MOITA LOPES, 2006/2016, 2013) e inconclusiva ${ }^{6}$ (DERRIDA, 1972/1991). Munidos de 'sensibilidade etnográfica', nosso propósito aqui é o de realizar uma análise aprofundada sobre nosso objeto de estudo, com base em um instrumental teórico-analítico definido.

Publicada no canal do Youtube 'Manifesto das 7', a vídeo-crítica a ser analisada é um exemplo de como as TICs (Tecnologias da Informação e Comunicação), além de facilitarem

\footnotetext{
${ }^{4}$ Disponível em: https://www.dicionariodenomesproprios.com.br/vicente/. Acesso em 28 jun. 2018.

${ }^{5}$ Nesse artigo, consideramos texto como qualquer conjunto coerente de signos (BAKHTIN [1959-1961] 2003: 305).

${ }^{6}$ Para Derrida (1972/1991), o significado nunca está pronto.
} 
a realização e veiculação de registros multimídia, também propiciam os meios para fazê-los circular mais ampla e intensamente, expondo-os a possíveis recontextualizações, a serem objeto de interações e/ou apropriações, como a por nós efetuada.

Dentre as muitas plataformas de interação na web, o Youtube destaca-se por ser um híbrido de rede social com buscador. Recuero $(2009$, p. 72$)$ define rede social como "um conjunto de atores e suas relações", que ampliaram as possibilidades de conexão e a capacidade de difusão de informações. Além de destacar o potencial destas conexões entre pessoas, Castells (2003) aponta que as redes sociais online constituem uma nova forma de interação. Logo, o Youtube, por tratar-se de um espaço onde valores são compartilhados, onde pessoas podem se relacionar e intercambiar informações, publicando/consumindo conteúdo audiovisual, seguindo/tornando-se youtubers e/ou interagindo por meio de comentários, abarcaria a alcunha rede social. Gabriel (2010), por sua vez, ressalta que o Youtube é a segunda plataforma online mais utilizada para efetuar buscas $^{7}$. De fato, um dos pesquisadores envolvidos na investigação que culminou neste artigo, usuário frequente do Youtube, deparou-se com a vídeo-crítica que embasa a análise ao acessar a plataforma para efetuar buscas relacionadas com o cineasta Pedro Almodóvar.

Feito este breve parêntese, reiteramos que neste artigo, em que o ato de nomear ocupa papel fundamental, entendemos que este, bem como qualquer outro ato de fala, nunca é neutro e desinteressado. É uma forma de "fazer coisas" por meio da linguagem (AUSTIN, 1962/1990), de agir no mundo social (MOITA LOPES, 2006/2016). Também de enquadrá-lo, dimensioná-lo e perspectivizá-lo. Carr e Lempert (2016), ao versarem sobre escalas, propõem um instrumental teórico-analítico que nos ajuda a identificar como isto se dá. Deste faremos uso para analisar a vídeo-crítica mencionada, além de propor interseções entre a noção de escala e o processo de construção cinematográfica, entre os estudos da linguagem e a sétima arte. Também recorremos à indexicalidade (SILVERSTEIN, 2003) e, de modo complementar, a três construtos propostos por Irvine e Gal (2000): iconização, apagamento e recursividade fractal.

Em termos de diferenciais, destacamos o uso inovador que propomos para certos conceitos: o ferramental apresentado por Irvine e Gal (2000), recentemente revisto por uma das autoras (GAL, 2016), articulado para ser empregado em análises sobre ideologias linguísticas, será usado aqui para identificar os processos semióticos projetados por ideologias que incidem sobre o gênero e a sexualidade. Cabe, ademais, mencionar o exercício metaescalar e reflexivo de não só efetuar a análise mas de refletir sobre a mesma e os instrumentos empregados para empreendê-la.

Para levar a cabo este trabalho nos termos estipulados, seguimos os seguintes passos: primeiramente, localizamos o tema central da crítica a ser analisada (a redesignação de gênero) e o relacionamos com teorizações queer de forma a embasar a discussão. Depois, debruçamo-nos brevemente sobre o filme que inspira a referida crítica ('A pele que habito'). Logo detalhamos o instrumental teórico-analítico, efetuamos a análise e tecemos as considerações finais.

\footnotetext{
${ }^{7}$ Segundo Gabriel (2010), a primeira é o Google.
} 
O filme de Almodóvar, assim como a vídeo-crítica que o analisa, gira ao redor de um processo transexualizador. Isto nos brinda com a oportunidade de debater, dentre outras questões, o modo como certas perspectivas forjadas no discurso sobre o gênero (determinismo biológico, voluntarismo) projetam entendimentos que se afiançam como hegemônicos ( cis $^{8}$-heteronormatividade), entendimentos estes que as teorias queer se ocupam de desconstruir.

Examinar a etimologia das palavras 'determinismo'9 e 'biológico'10 antes de aprofundar-nos no tema pode resultar elucidativo. A palavra 'determinismo', derivada do latim 'terminare', significa terminar, limitar. Se a este item lexical adicionamos o prefixo 'de', que indica movimento 'de um lugar ao outro' ou 'para fora', o determinismo consistiria em limitar movimentos, cercear o que se manifesta. Sintetiza, portanto, a ideia que o conceito 'determinismo biológico' encerra: limitar o que algumas performances poderiam manifestar/exteriorizar/por "para fora". Em outras palavras: o determinismo biológico apontaria para a imposição de limites, para restrições a diferentes formas de se estudar/conhecer/conceber ('logia') a vida ('bio'), para estratégias de controle sobre aquilo que manifestamos, para mecanismos que estabilizam sentidos. Tal mecanismo opera tomando 'por dada' a relação entre caracteres sexuais exteriores e o desempenho de certas performances: dependendo da genitália, o sujeito deverá performar feminilidade (caso tenha vagina) ou masculinidade (caso tenha pênis). Deverá, igualmente, manifestar desejo erótico-afetivo por pessoas cujo sexo designado se oponha ao seu. De acordo com Butler (1990/2007), a convergência entre sexo-gênero-desejo é um dos principais alicerces sobre os quais se funda a cis-heteronormatividade.

Butler (1990/2007) desconstrói esta associação tricotômica ao afirmar que o sexo sempre foi o gênero: ambos são produto dos sentidos que sobre eles depositamos. Butler (1990/2007), desse modo, implode a ideia de que haveria uma essência imutável calcada em uma imposição da natureza. Para melhor explicá-la, cunha o conceito 'performatividade de gênero'. Este se baseia no fato de que, para performances de gênero serem estabilizadas e padronizadas, cria-se a ficção de que existiria uma matriz heterossexual que atribui caráter inato, fixo e rígido a dois sexos-gêneros, construídos como opostos complementares. Esta matriz heterossexual, que se sustenta graças à manutenção de uma ordem compulsória, forja "a aparência de substância, de uma classe natural de ser" (BUTLER, 1990/2007, p. 98) e orienta modos de agir cisheterossexualmente 'coerentes'. Esta aparência de substância, fruto do efeito subjetivante e naturalizador que certas performances projetam, é o que a performatividade produz.

\footnotetext{
8 Adicionamos o prefixo 'cis', que significa identificação com o gênero assignado, à noção de heteronormatividade (BUTLER, 1990/2007) para ressaltar que não basta que o desejo seja heterossexualmente orientado: as performances de gênero devem ser desempenhadas em coerência com o gênero designado.

${ }^{9}$ Disponível em: https://pt.wikipedia.org/wiki/Determinismo. Acesso em 12 jul. 2018.

${ }^{10}$ Disponível em: hhttps://www.significadosbr.com.br/biologia. Acesso em 12 jul. 2018.
} 
Tal entendimento sobre o gênero, por diferenciar performance (ato) de performatividade (sentidos projetados pela repetição de atos) e por destacar que tais atos são constrangidos por "um marco regulatório altamente rígido (BUTLER, 1990/2007), não sendo, portanto, produto de uma vontade circunstancial, de um desejo pontual, também faz ruir a perspectiva voluntarista. Logra-se, desse modo, operar múltiplas desconstruções, que nos livram de resvalar em concepções voluntaristas e essencialistas/determinísticas, as quais negligenciam que é a força da repetição que produz significados (DERRIDA, 1972/1991). Ao expor o funcionamento da engrenagem heteronormativa e seu alicerce de sustentação, ou seja, o determinismo biológico, a performatividade, conceito nevrálgico das teorias queer, explicita que nós fazemos gênero, que não há uma essência que nos predisponha a desempenhar determinadas performances. Estas, por mais que sejam balizadas por um "marco regulatório altamente rígido" (BUTLER, 1990/2007, p. 98), não são por tais constrangimentos assujeitadas (FOUCAULT, 1982/1995). Tanto podem reificar sentidos que se cristalizaram por força da repetição como desafiá-los.

Performances de gênero e sexualidade desafiadoras abundam nas práticas sociais assim como na cinematografia de Almodóvar. Poucos cineastas que trafegam em circuito comercial têm levado às telas questões que expõem as fissuras do mecanismo heteronormativo como o cineasta espanhol.

\section{PELES HABITÁVEIS E O CINEMA DE ALMODÓVAR}

Transformar algumas de suas obsessões e/ou a maneira de abordá-las em marcas registradas, em um diferencial temático-estilístico, é uma das virtudes de Almodóvar. Questões que envolvem performatividades de gênero, especialmente aquelas que questionam pressupostos cis-heteronormativos, dentre as quais destacam-se performances de transgeneridade, são algumas destas obsessões, que inspiraram pesquisas sobre os seus filmes, realizadas recentemente no campo de estudos da linguagem no Brasil (VELOSO, 2012; QUEIROZ, 2017; GONZALEZ; MOITA LOPES, 2015, 2016, 2018).

Em 'A pele que habito', tais questões ganham centralidade na narrativa. $\mathrm{O} 18^{\circ}$ longametragem de Almodóvar conta a história de um médico empenhado em criar uma pele ultrarresistente depois que a esposa se suicida (ela tira a própria vida ao perceber o quão desfigurada fica após sofrer um acidente de carro). Em seus experimentos, o Dr. Robert usa como cobaia o rapaz que supostamente teria estuprado sua filha, submetendo-o também a uma cirurgia de transgenitalização. Logo, tal como Pigmaleão, apaixona-se por sua criatura.

Outras informações sobre o filme serão facilitadas na análise da vídeo-crítica produzida pelo youtuber Gabriel Tosto, que coloca o filme em perspectiva por meio de um exercício escalar-avaliativo. Este, por sua vez, é perspectivizado por nós pesquisadores neste trabalho, configurando, portanto, um exercício meta-escalar. 
Esta seção comporta tanto uma abordagem reflexivo-comparativa quanto teóricoanalítica da noção de escala (CARR; LEMPERT, 2016). Além de detalharmos como o construto será empregado na análise, estabeleceremos analogias entre o que aqui entendemos por escala no discurso e questões que remetem à construção da semiótica cinematográfica, justificando, assim, o seu emprego em análises que enfocam narrativas fílmicas. Julgamos ser este um exercício útil para refletir sobre a dupla perspectivização que analisar uma crítica envolve: colocar em perspectiva a perspectiva de outrem.

Todo filme, assim como todo discurso, envolve exercícios escalares de perspectivização, seja do nosso entorno (CARR; LEMPERT, 2016), seja do que que é mobilizado na narrativa fílmica. É, portanto, resultado de processos escalares, aqui entendidos como aqueles que literalmente enquadram certos temas, dimensionando-os. $\mathrm{O}$ ato de enquadrar, do ponto de vista cinematográfico, consiste em perspectivizar o que será contemplado dentro dos limites horizontais e verticais do enquadramento e em sinalizar o modo como isto será imageticamente dimensionado (o plano pode ser mais aberto ou fechado; o ângulo pode variar).

$\mathrm{O}$ ato de enquadrar, talvez a ação mais básica que dá materialidade ao processo cinematográfico, mobiliza escalas que projetam visibilidade e invisibilidade, definindo, à consequência disso, matrizes de inteligibilidade (DELEUZE, 1990), o dentro/fora (DERRIDA, 1973), que pode tanto estabelecer relações dicotômicas como complementares.

Se ao enquadrar determinamos o que pertencerá à escala do visível (dentro do campo) e do invisível (extracampo), posicionamo-nos, valha a redundância, ao posicionar o que enquadramos (CARR; LEMPERT, 2016), de modo que não há neutralidade na relação que se estabelece entre o que jaz dentro e fora do quadro, nem no enquadramento resultante. Recortes são fruto de seleções efetuadas, de escolhas que resultam na composição imagética. Podem engrandecer ou diminuir, dar maior ou menor destaque a algo, favorecer aquilo que se retrata, ou, pelo contrário, prestar-lhe um desfavor. Quando enquadramos, colocamos em prática estratégias que orientam a percepção, assumimos um ponto de vista, privilegiamos uma determinada perspectiva, demarcarmos pontos de vantagem (CARR; LEMPERT, 2016).

Pensar o enquadramento, bem como outros meandros da semiótica da construção cinematográfica sob uma ótica escalar (CARR; LEMPERT, 2016), permite-nos ampliar horizontes (contemplar a noção de escalas de maneira mais elástica e versátil) e nos faz atinar para a manipulação de espaços-tempos (recortes espaciais e elipses temporais), a forma como as escalas são forjadas (pontos de vista projetados) e o modo como estas podem ser (des)naturalizadas.

Olhar para a maneira como a ilusão de movimento é forjada pelo cinema ajuda a ilustrar como processos de (des)naturalização têm lugar. Para se reproduzir cinematograficamente o movimento, produto que o encadeamento sequencial de uma 
série de fotografias projeta, roda-se a 24 quadros por segundo ${ }^{11}$. Esta é a escala/proporção a que se chega para 'enganar o olho', para fazer com que o movimento, que é artificialmente construído, pareça natural. Deleuze (1985) chama este artifício de "imagem-movimento" 12. Porém, do mesmo modo que o movimento pode ser naturalizado, assemelhando-se à forma como é convencionalmente percebido, este também pode ser desnaturalizado. É possível manipulá-lo na diegese ${ }^{13}$ (GAUDREAULT; JOST, 2005/2009) por meio de alterações na escala padrão (câmera lenta/rápida, jump cuts $^{14}$, imagem congelada). Também através da perspectiva (a ação pode ser registrada com a câmera parada ou em movimento) e de recortes espaciais e elipses temporais (que vão determinar, respectivamente, por onde o espectador pode 'se mover' e a maneira como a narrativa avança).

Muitos destes pontos, merecendo destaque o modo como o ato de enquadrar circunscreve temporalidades às imagens resultantes, serão contemplados na análise. Tanto no caso da crítica como no caso do filme, que é pontuado por flashbacks e não segue uma ordem cronológica, registram-se saltos que atravessam diferentes espaçostempos. Estes, como veremos mais adiante na análise, ao serem manipulados pelo cineasta e pelo youtuber, dão-nos pistas sobre os discursos orientadores com os quais ambos operam. Por isso fazemos uso da noção de escalas (CARR; LEMPERT, 2016) em interseção com a de indexicalidade (SILVERSTEIN, 2003), que nos faz atentar para o laço indexical que se estabelece entre o signo que é evocado em um dado ato comunicativo e os discursos orientadores para os quais este aponta.

Processos escalares, em suma, englobam indexicalidade, movimentação espaçotemporal, analogias e distinções, dimensionamentos, avaliações. Inspiram/delatam (auto)posicionamentos e podem levar a hierarquizações, que, como tais, envolvem jogos de poder (CARR; LEMPERT, 2016). Também são mobilizados para ordenar, agrupar, categorizar coisas/pessoas/ideias/situações, estabelecer pontos de vantagem e para ajudar atores sociais a orientarem/interpretarem/agirem em seus mundos (CARR; LEMPERT, 2016). Logo, este será o principal ferramental a nortear a análise, que será complementada por três construtos teórico-analíticos propostos por Irvine e Gal (2000): iconização, apagamento e recursividade fractal.

É possível, através de um exercício escalar baseado em analogias, estender/redimensionar os usos destes construtos para além do emprego inicialmente previsto (analisar a linguagem em uso). Buscamos fazer isso, já que os mesmos resultam-nos úteis

\footnotetext{
${ }^{11}$ Esta proporção remete ao padrão mais usual quando se rodava com película $35 \mathrm{~mm}$, distando dos padrões estabelecidos por outras tecnologias (digital) e suportes (vídeo/magnético).

12 Deleuze (1985) nos aponta como a escala da ficção no cinema clássico narrativo é construída para criar a sensação de que os planos são naturalmente encadeados, forjando a sensação de movimento contínuo. Dessa maneira, dissimula-se a forma como o filme é produzido para criar a aparência de naturalidade.

13 Segundo Gaudreault e Jost (2005/2009), diegese é a relação de coerência que faz com que determinadas situações tenham sentido dentro de um universo ficcional, fazendo com que certos eventos, ainda que implausíveis em escalas não ficcionais, adquiram verossimilhança dentro de uma dada narrativa.

${ }^{14}$ Consiste na eliminação de quadros/fotogramas de um plano e tem por efeito produzir saltos na imagem, rompendo com a continuidade linear do movimento. Este recurso foi muito usado por cineastas como JeanLuc Godard durante a Nouvelle Vague, movimento cinematográfico francês. Para mais informações: http://obviousmag.org/archives/2012/07/nouvelle_vaugue_jump_cut_e_a_destruicao.html.
} 
para auxiliar na análise proposta, explicitando mecanismos que projetam hegemonias, criam e dão materialidade a diferenças, assimetrias e hierarquizações linguístico-semióticas. Do mesmo modo que as ferramentas idealizadas por Irvine e Gal (2000) nos dão pistas sobre como se forjam hegemonias que se afiançam no terreno linguístico, caso da norma culta e seus falantes, estas ferramentas igualmente podem ajudar a evidenciar aspectos semióticodiscursivos mais amplos que alicerçam a hegemonia cis-heteronormativa.

Se a iconização pode ser definida como o processo que estabelece uma correlação entre determinadas características linguísticas e a imagem social a qual estão associadas (IRVINE; GAL, 2000), o que envolve, muitas vezes, o estabelecimento de "conexões aparentemente diretas, automáticas e naturais" (BRIGGS, 2007) que seriam supostamente capazes de captar "a natureza ou a essência inerente a um grupo social" (IRVINE; GAL, 2000 , p. 37), esta noção também poderia ser empregada para apontar o modo como o gênero é hegemonicamente perspectivizado ou os mecanismos semióticos que fazem com que adquira a "aparência de uma substância" (BUTLER, 1990/2007, p. 98). Da mesma maneira que características/práticas linguísticas, interpretadas como típicas e definidoras das 'identidades' sobre as quais operam, a reiteração de performances de gênero, também produz efeitos subjetivantes. Tal mecanismo, segundo Foucault (1976/1998), é o que faz com que certas práticas, como a 'sodomia', por exemplo, deixem de ser contempladas como o que são (realização de uma ação) e passem a enclausurar aquele que a pratica em uma espécie (no caso, a homossexual). Logo, a iconização, seja esta sustentada por ideologias linguísticas ou por ideologias que permeiam nosso entendimento acerca do gênero, ao atar o sujeito a uma determinada 'identidade social', poderia conduzir tanto à imobilidade sociolinguística (PINTO, 2013), quanto à imobilidade no que tange ao modo de performar o gênero e a sexualidade.

O apagamento, por sua vez, é o processo pelo qual estas conexões entre características projetadas e imagem social são criadas e mantidas graças a elipses (IRVINE; GAL, 2000). O apagamento consiste na eliminação de traços/matizes que possa constituir uma ameaça à ideologia que se pretende instaurar/preservar. Já a recursividade fractal se caracteriza por projetar "uma oposição, saliente em algum nível da relação para algum outro nível" (IRVINE; GAL, 2000, p. 38). Trata-se, como sinaliza Moita Lopes (2013), de um processo escalar, que se baseia em projeções dicotômicas, em opor uns a outros, beneficiando uma das partes. Este construto, assim cunhado pelas autoras por remeter a processos que abrangem repetições (recursividade) e conservam algo da estrutura que espelham (fractal), mostra-se efetivo quando se trata de identificar "fenômenos que envolvam segmentação ou cismogênese, como ideologias nacionalistas e rituais de gênero" (IRVINE; GAL, 2000, p. 38). Logo, torna-se pertinente seu emprego no caso do qual nos ocupamos.

\section{PROJEÇÕES (META)ESCALARES}

Será objeto de análise um excerto da vídeo-crítica cinematográfica intitulada 'A Pele que Habito e a Ideologia de Gênero' ${ }^{15}$. Elaborada pelo youtuber Gabriel Tosto, a vídeo-crítica foi publicada no dia $1^{\circ}$ de novembro de 2017 no canal 'Manifesto das 7', criado "para falar e discutir arte em todas as suas vertentes".

\footnotetext{
${ }^{15}$ Disponível em: https://www.youtube.com/watch?v=VWN438rDjhw. Acesso em: 14 ago. 2018.
} 
Em consulta efetuada no dia 19 de junho de 2018 às 10:28 da manhã, horário de Brasília, dos 22 vídeos disponibilizados para visualização (desconhecemos se os administradores mantêm publicações com algum tipo de restrição), este era o terceiro mais comentado e o quarto mais visto. Com duração de 12'52', o vídeo totalizou 26.097 visualizações e inspirou uma interação online que rendeu 59 comentários, além de réplicas e tréplicas, tendo sido o último comentário publicado em junho de 2018. Convém destacar este fato porque o filme, que estreou no Brasil no dia 4 de novembro de 2011, continua, sete anos depois, cumprindo ampla trajetória textual (BLOMMAERT, 2005) por meio de processos de recontextualização, assim como a vídeo-crítica de Gabriel, publicada há mais de um ano.

Feitas estas considerações iniciais para contextualizar a análise, efetuamos agora a transcrição do excerto, tomando como referência o método proposto por Rose (2002, p. 350) para cobrir o aspecto visual e marcas ${ }^{16}$ adaptadas de Gumperz (1992) para as falas. Na sequência, dedicamo-nos à análise.

Transcrição:

\begin{tabular}{|l|l|l|l|}
\hline Sequência $^{17}$ & Dimensão visual & Dimensão verbal & $\begin{array}{l}\text { Dimensão } \\
\text { sonora }\end{array}$ \\
\hline 1 & $\begin{array}{l}\text { 0:02:49:11 } \\
\text { Gabriel, enquadrado à altura da } \\
\text { cabeça e acima do abdômen, fala } \\
\text { para a câmera. }\end{array}$ & $\begin{array}{l}\text { TOk.. Vamos começar então pela } \\
\text { construção dos personagens... Todos } \\
\text { os persona::gens possuem um perfil } \\
\text { moral dúbio.. }\end{array}$ & som direto \\
$\begin{array}{l}\text { Com as duas mãos, sinaliza } \\
\text { movimento de um ponto a outro. }\end{array}$ & $\begin{array}{l}\text { Estando sempre <entre a inocência e } \\
\text { a malícia>.. } \\
\text { Move a cabeça e gesticula com a } \\
\text { mão direita. }\end{array}$ & $\begin{array}{l}\text { Saca aquele este- estereótipo do } \\
\text { doutor e do monstro? Pode parecer } \\
\text { uma:: referência direta ao Doutor } \\
\text { Robert, mas isso acontece com } \\
\text { qua::se todos os personagens no } \\
\text { filme. Por exemplo.. a governanta da }\end{array}$ & \\
\hline
\end{tabular}

\footnotetext{
${ }^{16}$ Símbolos

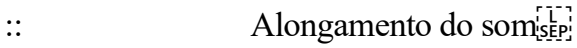

个 Entonação ascendente

$\downarrow \quad$ Entonação descendente

$<>\quad$ Fala mais lenta

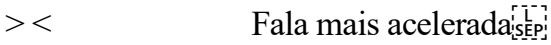

- $\quad$ Interrupção da fala

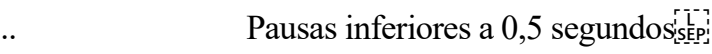

... Pausa superior a 0,5 segundos (sem ter sido precisamente cronometrada)

Sublinhado Sílaba ou palavra enfatizada

${ }^{17}$ Sequência é o conjunto de planos que, ao serem encadeados, adquirem unidade dramática (GAUDREAULT; JOST, 2005/2009). Dividimos o excerto a ser analisado em sequências da vídeo-crítica protagonizadas pelo youtuber e fragmentos do filme nesta inseridos.
} 


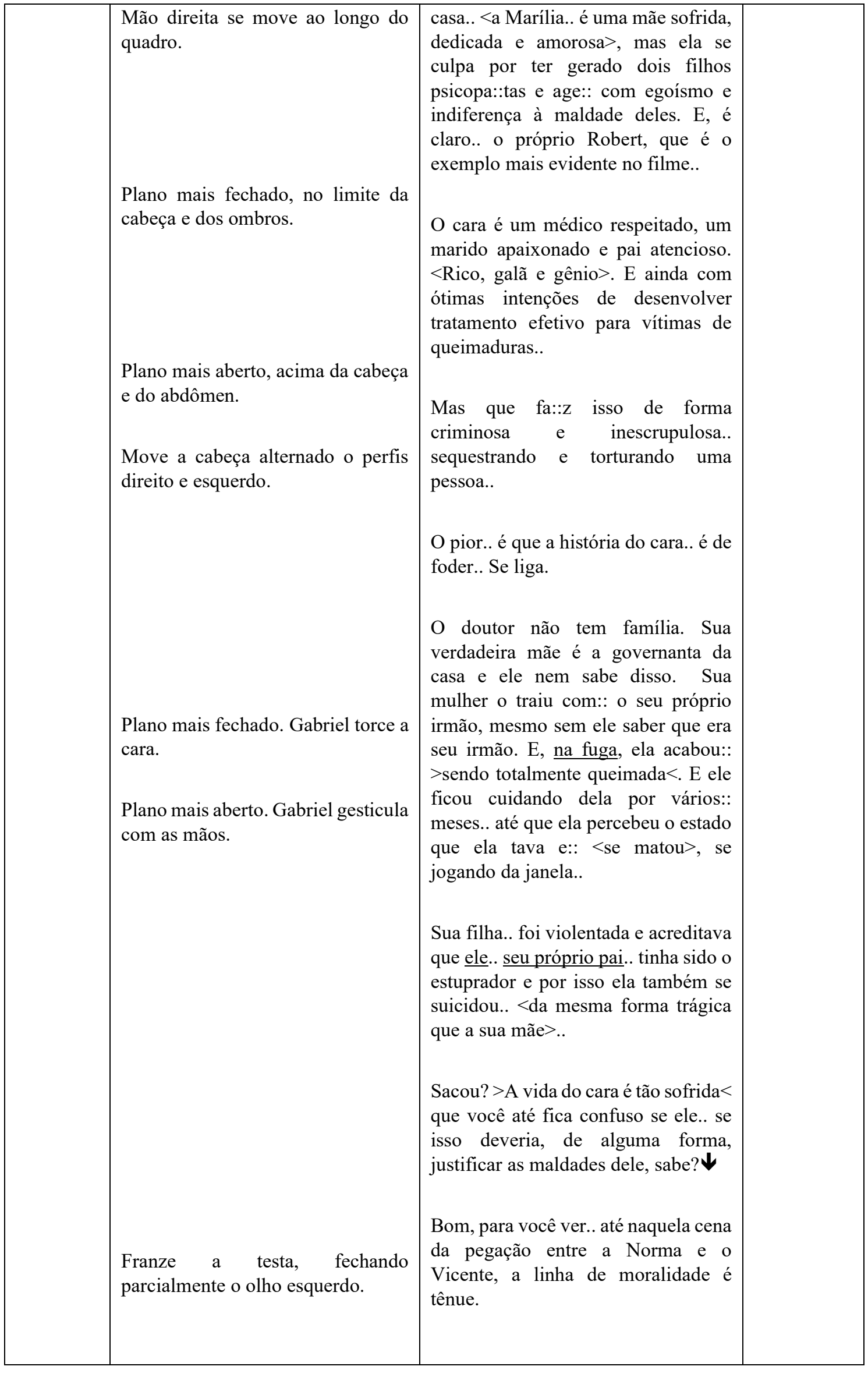


Afasta os braços com as palmas da mão para cima.

Plano mais fechado. Gabriel estende o braço direito em direção à câmera.

Plano mais aberto. Gabriel gesticula com as mãos próximas.

De perfil, aproxima-se da câmera gesticulando com o braço direito.

2 Cena do filme em que o rosto de Vicente gradualmente desaparece e dá lugar ao de Vera.

$0: 05: 31: 16$

Gabriel gesticula com os braços.

De perfil, em plano mais fechado, Gabriel encara a câmera.

Em plano mais aberto, Gabriel, aproxima as mãos do corpo.
个Por um lado.. Vicente é inocente das acusações de ter estuprado a menina.. Pois, até então, os dois estavam se curtin::do e devido à condição psicológica de Norma.. ela acabou tendo um surto psicótico.. $<$ Por outro lado $>$.. ele:: estava chapado, entrou em pânico e é culpado de ter agredido a menina e ter fugido deixando ela desacordada.

Para mostrar como essa definição pode ficar ainda mais complicada.. Quando Vicente passa a ser Vera.. é ele quem é estuprado e $<$ a fronteira entre o medo, o desejo e a impotência $>$ são cada vez mais indistinguíveis nessas cenas..
Essa coisa ambígua da moralidade é também parte da construção que Almodóvar faz para te fazer pensar sobre a questão de gênero, invertendo os papéis nessa discussão. No filme, é mais ou menos assim que a coisa funciona.. Imagine que você tenha nascido $<$ homem e hetero $>$, mas, por uma situação forçada, você acorda de um dia para o outro, com o corpo de uma mulher.

E hoje em dia i::sso é possível, parceiro. Não é:: ficção, não. $\downarrow$

$>$ Pois bem $<$, acontece que:: apesar de você:: agora possuir um corpo de mulher, ser até batizado com um nome de uma mulher, ser obrigado a usar roupa de mulher e todo mundo te enxergar apenas como uma mulher.. você continua sendo homem个 porque essa é a sua:: essência. Entende? O gênero masculino.. está na sua constituição psicológica... apesar de todo o resto sugerir o contrário. $\mathrm{Ou}:$ : você mudaria.. o seu gênero? 


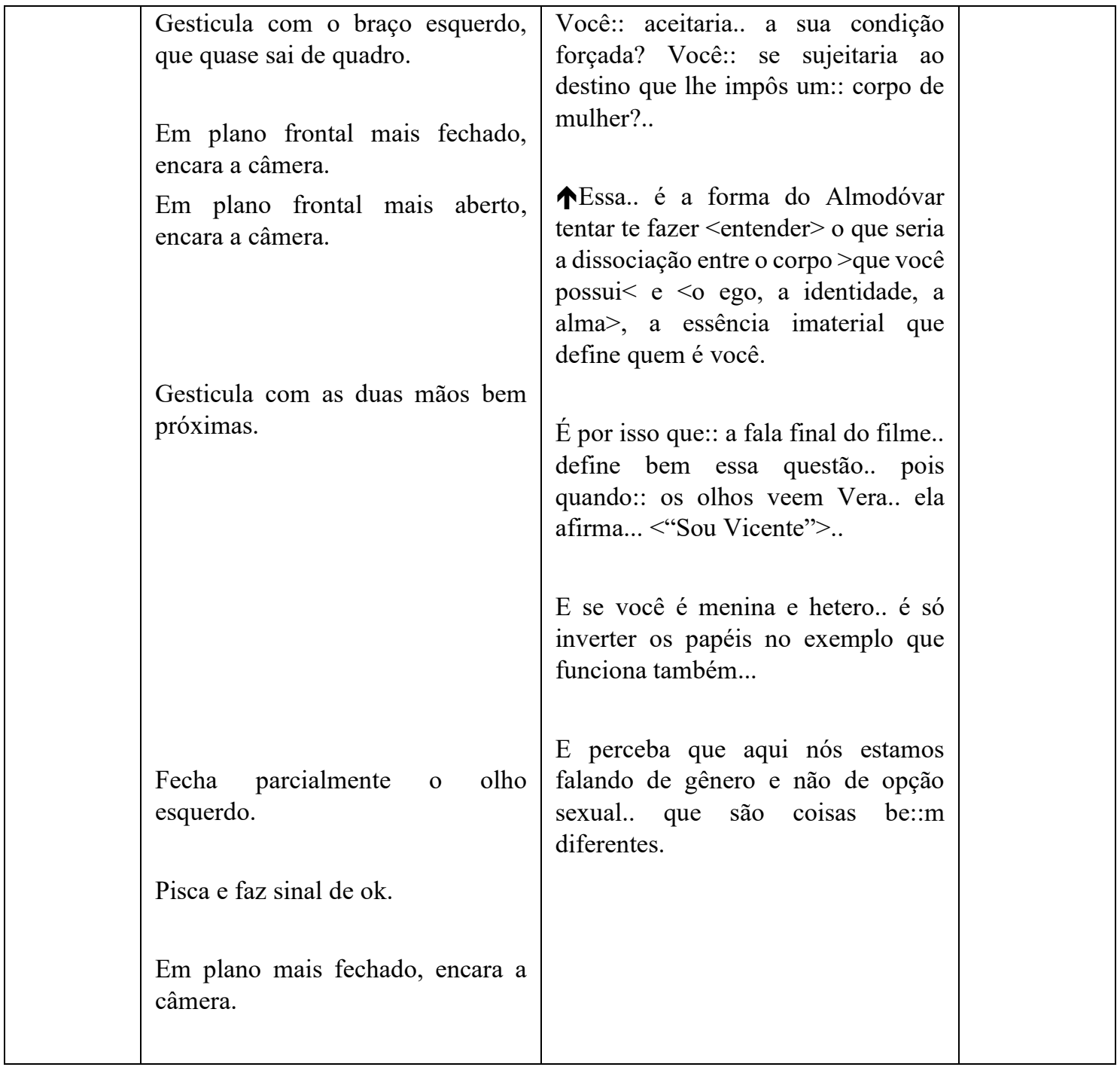

Neste excerto, que tem início transcorridos 2'49' do vídeo e finda aos 7'09', Gabriel, após tecer considerações introdutórias, propõe começar a crítica, que envolve um processo de recontextualização do filme, "pela construção dos personagens". O youtuber projeta sobre estes uma escala de "moral dúbia". Movendo a mão direita, emprega um tom didático ao ilustrar o seu ponto de vista com uma citação: “ヤSaca aquele este-estereótipo do doutor e do monstro? Pode parecer uma:: referência direta ao Dr. Robert, mas isso acontece com qua::se todos os personagens no filme".

Enquanto a entonação ascendente poderia ser interpretada como uma tentativa de projetar/reivindicar uma escala de autoridade, a menção ao "estereótipo do doutor e do monstro" aponta tanto para um exercício escalar reducionista e monolítico (TSING, 2015), posto que se calca em um estereótipo - em uma iconização (IRVINE; GAL, 2000) -, como para dinâmicas de recursividade fractal (IRVINE; GAL, 2000), já que se baseia em uma oposição (médico $\mathrm{x}$ monstro) que inspira novas oposições (controle $\mathrm{x}$ descontrole, correção x aberração). Novo exercício escalar estende estas projeções estereotípicas e dicotômicas, que inicialmente recairiam apenas sobre o médico, a "qua::se todos os personagens do filme", o que Gabriel enfatiza por meio do alongamento da vogal. 
Este fragmento, além de apontar para o caráter referencial que permeia esta prática discursiva, evidencia que uma crítica consiste em um exercício escalar por excelência, posto que se baseia na avaliação daquilo que tomamos por objeto de análise (CARR; LEMPERT, 2016), bem como em seu dimensionamento e interpretação. Soma-se a isso o fato de que nós, ao mesmo tempo que posicionamos tal objeto, também nos posicionamos e o fazemos dentro de uma escala espaço-temporal. Gabriel, por exemplo, ao sinalizar que a moral dos personagens é dúbia e projetar uma escala comparativa ao citar a obra de Robert Louis Stevenson, 'O médico e o monstro', publicada em 1886 e também conhecida como 'Dr. Jekyll e Mr. Hyde', transita entre diferentes espaços e temporalidades: o Brasil contemporâneo (que é o lugar do qual ele nos fala e, portanto, o que ancora seu ponto de vista), a Londres de final do século XIX (momento em que a obra de Stevenson foi publicada) e a Espanha de anos recentes (a história é localizada no tempo 'presente', que nos remete ao ano de 2011, quando o filme foi lançado, mas é pontuada por diversos flashbacks, alternando diferentes espaços-tempos). O youtuber, entretanto, não projeta analogias entre o protagonista do filme e o autor do livro referenciado, apesar de ambos terem o mesmo nome (Robert).

Depois de citar "o estereótipo do doutor e do monstro", que lhe serve de gancho para abordar a moral dúbia dos personagens, em especial a do doutor Robert, Gabriel nos conta um pouco da história do cirurgião numa tentativa de identificar o que teria levado "um médico respeitado, marido apaixonado e pai atencioso" a agir de forma inescrupulosa. E, perspectivizando eventos da trajetória de Robert, como, por exemplo, os suicídios da filha e da esposa, avalia, gesticulando e franzindo a testa: " $>$ A vida do cara é tão sofrida $<$ que você até fica confuso se ele.. se isso deveria, de alguma forma, justificar as maldades dele, sabe? $\downarrow$ ”. Com este posicionamento, o youtuber, que abre os braços deixando as palmas da mão para cima, o que poderia indicar que ele se rende ante as circunstâncias, apesar de titubear (pausa, aceleração da fala e mudança de entonação sugerem isso), isenta/perdoa Robert, redimensionando/atenuando a gravidade das atrocidades por ele cometidas.

Gabriel, que estende o braço direito em direção à câmera, convidando a/o espectador(a) a seguir seu raciocínio, também identifica signos de "moralidade dúbia" na "cena da pegação entre a Norma e o Vicente". Julga que "os dois estavam se curtin::do", o que é evidenciado pelo alongamento da vogal nasalada, e absolve Vicente ("é inocente das acusações de ter estuprado a menina"). Logo indexicaliza discursos que evocam a autoridade médica, do âmbito da psicologia mais especificamente, para reforçar a forma como perspectiviza a situação: "devido à condição psicológica de Norma.. ela acabou tendo um surto psicótico". O modo como Gabriel posiciona os personagens neste trecho (Vicente: inocente, Norma: surtada) acaba por posicioná-lo como alguém que, orientado por discursos de senso comum, ante uma situação que envolve vulnerabilidade, culpabiliza a pessoa que sofre violência pela violência padecida. Em seguida, porém, o youtuber volta a mencionar que, no filme, "a linha da moralidade é tênue" e redimensiona a questão: " $<$ Por outro lado $>$.. ele:: [Vicente] estava chapado, entrou em pânico e é culpado de ter agredido a menina e ter fugido deixando ela desacordada". Curiosamente, Gabriel, cujo gestual (mãos próximas uma da outra) indica uma postura mais introspectiva e reflexiva, em meio a mudanças de ritmo e alongamentos vocálicos, que deixariam transparecer uma certa insegurança, não usa como 'atenuante jurídico' o fato 
de Vicente estar "chapado" para abrandar outras acusações contra o rapaz ("ter fugido deixando ela desacordada"). Projeção escalar comumente usada em juízos, este tipo de projeção baseia-se na suposição de que alguém que não esteja em suas plenas faculdades, torna-se incapaz de responder por seus atos, logo suas ações não teriam dolo. $O$ fato de Vicente ter fugido sem prestar auxilio é justificado por Gabriel ("entrou em pânico), mas não é atenuado ("é culpado de ter agredido a menina").

No que tange à ordem de discurso médico-psicológica (FOUCAULT, 1963/1980), o que se observa é que Gabriel a indexicaliza para investir de autoridade a avaliação que faz da cena em questão. O elo simbiótico entre conhecimento-autoridade/saber-poder (FOUCAULT 1982/1995) estabelece "pontos de vantagem" e possibilita que uma perspectiva escalar se sobreponha a outras (CARR; LEMPERT, 2016). Como consequência, esta perspectiva pode se tornar hegemônica e os discursos que a sustentam passam a gozar de ampla aceitação, sendo, muitas vezes, naturalizados. Carr e Lempert (2016) nos alertam do perigo de naturalizar escalas, de não questionar discursos "intensivamente institucionalizados", como os de ordem médica (FOUCAULT, 1963/1980). Estes, além da ampla escalabilidade que os caracteriza, projetariam 'verdades' de forma monolítica (TSING, 2015), supostamente imune a questionamentos. É o que se observa, por exemplo, na atribuição de histeria às 'mulheres' 18 (ALONSO; FUKS, 2004), de uma presumida condição psicológica mais frágil e/ou emocionalmente instável. Tais discursos, que têm se mostrado historicamente efetivos na desqualificação do sujeito designado socialmente como 'mulher', o qual, para o seu "próprio bem" e da sociedade como um todo, deve estar sob resguardo de uma autoridade masculina, geralmente do pai ou do marido (BADINTER, 1980/1991), são evocados quando Gabriel fala de Norma. Não surpreende que o personagem, como acima apontado, seja assim nomeado.

O youtuber, ao referenciar/qualificar como "surto psicótico" a reação de Norma sem explicar/mencionar os acontecimentos prévios que a deixam em tal estado, ao mesmo tempo em que usa isso para justificar a reação agressiva de Vicente, parece corroborar discursos de senso comum que estabelecem correlações entre histerias e performances de feminilidade (ALONSO; FUKS, 2004), além de 'autorizarem' respostas violentas. Em contrapartida, Gabriel opera uma série de saltos escalares ao elencar eventos narrativos que pertencem a outros espaços-tempos (a traição da esposa, o suicídio dela e o da filha) a fim de justificar o porquê de Robert ter cometido determinadas 'maldades', redimensionando-as (" $>$ A vida do cara é tão sofrida< que você até fica confuso se ele.. se isso deveria, de alguma forma, justificar as maldades dele, sabe? $\downarrow$ "). Esse tratamento diferenciado leva-nos a concluir que os parâmetros escalares utilizados por Gabriel para avaliar/dimensionar/referendar/justificar as (re)ações dos personagens masculinos divergem dos que ele utiliza para julgar as (re)ações de Norma. O youtuber, ademais, parece ecoar discursos de senso comum, que, em suas entrelinhas, deixam antever traços de misoginia e machismo.

Na sequência, Gabriel, que passa a encarar a câmera de perfil, continua versando sobre a (linha de) moralidade dos personagens, qualificada como "tênue" e "complicada". Em

${ }^{18}$ Colocamos mulher/mulheres entre aspas ao longo do texto, exceto nas citações diretas, porque, coadunandonos com Butler (1990/2007, p. 52), acreditamos que tal categoria precisa ser problematizada: não deve projetar "um sujeito coerente e estável". 
seguida, o youtuber utiliza eventos da escala/dimensão da narrativa para embasar seu posicionamento: "essa definição pode ficar ainda mais complicada.. Quando Vicente passa a ser Vera..". Logo ressalta que o cineasta te faz "pensar sobre a construção de gênero, invertendo os papéis nessa discussão". Esta inversão, uma projeção escalar que promove um deslocamento de sentidos, também se reflete nas performances de feminilidade e masculinidade, de algoz e vítima, que acabam se alternando e até mesmo se fundindo no filme.

Gabriel, à continuação, mobiliza três escalas ao propor que o espectador se coloque na pele do personagem: a escala das possibilidades (hipótese), a escala ficcional (filme) e a escala não ficcional (acontecimentos que seriam possíveis fora da narrativa cinematográfica). Desse modo, perspectiviza a questão que ocupa centralidade nesta investigação: a performatividade de gênero. Centremo-nos na fala de Gabriel, que passa a encarar a câmera e, por conseguinte, a/o espectador (a) de forma mais incisiva: "No filme, é mais ou menos assim que a coisa funciona.. Imagine que você tenha nascido $<$ homem e hetero $>$, mas, por uma situação forçada, você acorda de um dia para o outro, com o corpo de uma mulher. E hoje em dia i::sso é possível, parceiro. Não é:: fícção, não. $\downarrow$ ”. Mobilizar estas três escalas (hipotética, ficcional e não ficcional) resulta útil para o youtuber efetuar analogias e dimensionar eventos da narrativa. Estes, quando extrapolam a escala ficcional ("hoje em dia i::sso é possível, parceiro. Não é ficção"), ganham novo matiz, passando a transitarem entre a escala das possibilidades e a não ficcional, percepção esta que é enfatizada pelo alongamento vocálico. Este exercício, além de explicitar o caráter relacional-comparativo que operar com escalas envolve (CARR; LEMPERT, 2016), ao colocar o gênero em perspectiva, ajuda-nos a identificar o modo como este é atravessado por diferentes ideologias: há aquelas que apontam para uma compreensão de gênero como ficção/paródia (performatividade) e as que apontam para uma compreensão que nega este viés ficcional (determinismo biológico). Este exercício escalar também auxilia na sinalização de processos semióticos de iconização (a convergência entre sexo-gênero-desejo aponta para correlações que se naturalizam), apagamento (a cis-heteronormatividade se sobrepõe apagando outras escalas de possibilidades) e recursividade fractal (oposições escalares - 'mulher'/'homem', cis/trans, homo/heterossexual - encarceram/imobilizam o sujeito em um sistema dicotômico).

Este fragmento igualmente evidencia a concepção do youtuber acerca do gênero: se por um lado a metalinguagem empregada ("construção de gênero") pode ser associada a uma visão performativa de gênero (BUTLER, 1990/2007), por outro, mobiliza sentidos essencializantes. Gabriel, projetando tais sentidos em uma escala hipotética ("imagine que...") e atrelando-os às circunstâncias da narrativa fílmica ("situação forçada"), faz menção a "[nascer] homem e hetero", como se ecoasse uma sentença, similar à proferida pelo enunciado "é menina"/“é menino" (BUTLER, 1990/2007). Tais escolhas lexicais apontam para discursos que associam o gênero a uma escala biologicamente determinística (BUTLER, 1990/2007). Logo, mesmo reconhecendo enfaticamente (vide o alongamento de vogais) redesignações de gênero como possíveis não só na ficção ("hoje em dia i::sso é possível, parceiro. Não é:: ficção"), o youtuber parece vincular tais possibilidades apenas ao avanços da ciência/medicina, desconsiderando que a 'adaptação 
corpórea' por meio de cirurgia é apenas uma das dimensões que o processo de redesignação de gênero abarcaria. Tendo tal processo em tela, podemos identificar como certos discursos orientadores de alta escalabilidade (determinismo biológico, matriz cisheteronormativa, autoridade médico-científica), que se propagam de forma ampla e precisa (TSING, 2015), naturalizando escalas, referendando uma perspectiva essencializante, comparecem na fala de Gabriel.

O youtuber, ato seguido, sugere, dessa vez de forma literal, que há uma essência e que esta não poderia ser modificada: "acontece que:: apesar de você:: agora possuir um corpo de mulher, ser até batizado com um nome de uma mulher, ser obrigado a usar roupa de mulher e todo mundo te enxergar apenas como uma mulher.. você continua sendo homem个 porque essa é a sua:: essência. Entende?". O filme, entretanto, parece expor o contrário: Vicente aprende a performar o gênero que lhe foi cirurgicamente imposto. Gabriel, porém, novamente ecoa discursos essencializantes e projeta oposições naturalizadas (feminino x masculino), destacando e ratificando, por meio de entonação ascendente e alongamentos vocálicos, que o destino prescrito pela biologia é inalterável. $O$ youtuber chega a se exaltar ligeiramente nesse trecho, passando a gesticular de forma mais aberta (o braço esquerdo quase sai de quadro). Gabriel, ademais, usa o processo de transgenitalização forçado ao qual Vicente é submetido para insinuar que a cirurgia produziria efeitos apenas em escala superficial, no nível da aparência ("possuir um corpo de mulher"). Haveria uma dimensão mais profunda imune a mudanças ("você continua sendo homem $\uparrow$ porque essa é a sua:: essência. Entende?”). Fazem-se notar aí dinâmicas de recursividade fractal: a oposição aparência x essência inspira outras oposições binárias (sexo x gênero, mutabilidade x imutabilidade). Butler (1990/2007) as desconstrói ao afirmar que o sexo sempre foi o gênero, como já foi mencionado anteriormente.

Gabriel, à continuação, mobiliza outros discursos ao voltar a defender uma perspectiva essencializante: "O gênero masculino está na sua [de Vicente] constituição psicológica.. apesar de todo o resto sugerir o contrário. Ou:: você [espectador/a] mudaria.. o seu gênero?". Dessa vez, o youtuber, posicionado mais próximo da câmera, o que projeta uma escala de interpelação somática, ancora-se indexicalmente em discursos de ordem médico-psicológica e flerta, ainda que com certa ironia, acentuada pelo alongamento vocálico, com uma perspectiva voluntarista. Perspectiva esta que a definição de gênero de Butler (1990/2007, p. 98) desmantela ao explicitar que performances de gênero são constrangidas por um "quadro regulatório altamente rígido".

$\mathrm{Na}$ mesma sequência de questionamentos, marcada por pausas e mais alongamentos vocálicos, Gabriel, menos expansivo, gesticula com as mãos mais próximas do corpo, projetando para si aquilo sobre o que versa quando se detém a falar de destino: "Você:: aceitaria.. a sua condição forçada? Você:: se sujeitaria ao destino que the impôs um:: corpo de mulher?..". Curiosamente, o destino, tal como perspectivizado pelo youtuber nesta sentença, não é marcado pelo determinismo biológico mas por uma vingança de base médicocientífica. De qualquer modo, os efeitos por estas escalas projetados convergem: o impositivo médico-científico (no caso do filme, uma transgenitalização forçada), assim como o impositivo biológico (associação de caracteres sexuais exteriores ao desempenho de determinadas performances), seria capaz de influenciar o destino das pessoas, de produzir efeitos igualmente indesejáveis. 
Em seguida, Gabriel torna a se valer da credibilidade que o discurso médicopsicanalista (FOUCAULT, 1963/1980) teria para referendar seu ponto de vista, perspectivizando o que o cineasta teria proposto com o filme: “个Essa.. é a forma do Almodóvar tentar te fazer <entender $>$ o que seria a dissociação entre o corpo >que você possui $<$ e $<$ o ego, a identidade, a alma $>$, a essência imaterial que define quem é você". Nesse trecho, o youtuber, que adota um gestual mais contido depois de reivindicar atenção ao elevar o tom, tanto se vale tanto da prosódia (fala mais pausadamente em certo momento, ditando um ritmo quase didático) como de itens lexicais característicos do jargão psicanalítico ("ego") e religioso ("alma”). São muitas as escalas e ordens do discurso que Gabriel mobiliza para sustentar sua percepção, de cunho essencialista, a qual nos ocupamos de desconstruir por acreditar que, dentre os perigos que esta abarca, jaz o apagamento do modo como certos regimes de verdade se impõem, assim como a naturalização de discursos de alta escalabilidade (TSING, 2015). Estes discursos não apenas eliminam matizes dos processos semióticos que os envolvem, como também projetam "conexões aparentemente diretas, automáticas e naturais" (BRIGGS, 2007, p. 323), e dicotomizações, o que Irvine e Gal (2000) chamam, respectivamente, de iconização e recursividade fractal.

Gabriel, à continuação, numa projeção escalar que considera outra fatia do público (até então dirigia-se ao seu interlocutor usando a flexão de gênero no masculino), propõe com uma piscadela de olho: "se você é menina e hetero.. é só inverter os papéis no exemplo que funciona também...”. E, ato seguido, encara a câmera de forma direta e faz um alerta: "perceba que aqui nós estamos falando de gênero e não de opção sexual.. que são coisas be::m diferentes". Tal esclarecimento o projeta como alguém que teria conhecimento para versar sobre o tema do qual trata. No entanto, apesar de enfatizar, por meio do alongamento vocálico, que gênero e opção sexual são coisas "be::m distintas", o youtuber não se aprofunda na questão e, em seguida, muda de assunto, passando a enfocar as referências, sobretudo das artes plásticas, que pontuam o filme, as quais não são o foco deste artigo.

\section{ESCALABILIDADE}

O cinema projeta/forja mundos possíveis, edificados com base em recortes tergiversados pelo olho de quem enquadra/escala/dimensiona/perspectiviza. Isto buscamos mostrar ao aproximar a noção de escalas com a qual operamos (CARR; LEMPERT, 2016) de certos fundamentos acerca da construção da semiótica cinematográfica. Resultou-nos útil este percurso para empreender o exercício escalar aqui proposto: colocar em perspectiva a perspectiva de outrem sobre um filme, que é, por sua vez, a perspectiva de um cineasta sobre determinados temas, o que envolve diferentes recontextualizações. Este exercício, que mobiliza o encontro de múltiplas perspectivas, permitiu-nos levar a cabo nossa proposta metaescalar e reflexiva, que contempla tanto o objeto de análise como as ferramentas a serem empregadas para analisá-lo. Em termos analíticos, esta proposta se traduziu em reflexões sobre como o gênero é enquadrado/dimensionado/perspectivizado por Almodóvar no filme 'A pele que habito', logo por Gabriel em sua vídeo-crítica sobre a obra e finalmente por nós mesmos neste 
trabalho. E se o cinema se baseia em recortes, selecionando o que vai ser mostrado tomando como referência um ponto de vista específico, a vídeo-crítica, bem como esta análise, também o fazem.

Tendo em tela os recortes submetidos a escrutínio em nossa análise, aqui projetada como uma leitura dentre outras possíveis, há pontos que merecem destaque. Dentre eles, cabe menção às projeções escalares conflitantes: Gabriel fala em "construção de gênero", mas utiliza palavras como "destino" e "essência", que apontam para discursos essencializantes, ao perspectivizar o comportamento de Vicente/Vera. Por mais que afirme que o filme nos faz pensar sobre a construção de gênero, projetando que este seria o propósito de Almodóvar, o youtuber, seja de forma explícita ou nas entrelinhas de seu discurso, conforme sinalizamos na análise, mobiliza sentidos que remetem ao determinismo biológico e a uma perspectiva voluntarista, distando, portanto, do modo como as teorias queer, através de conceitos como 'performatividade' (BUTLER, 1990/2007), concebem o gênero como efeito de práticas reiteradas.

Em contrapartida, nós, pesquisadores, interpretamos que os sentidos mobilizados por Vicente/Vera na narrativa filmica sugeririam que o gênero é sempre performado (BUTLER, 1990/2007): não por casualidade, a/o protagonista logra desempenhar tanto performances de masculinidade quanto de feminilidade. Não só a feminilidade foi estrategicamente performada na narrativa com vistas a obtenção de determinados ganhos ${ }^{19}$ (sobrevivência, arquitetura de uma possível fuga), a masculinidade também: esta é manejada para levar a determinados fins (sexo, por exemplo). Isto nos induz a concluir que, em 'A pele que habito', as performances de gênero desempenhadas rompem com a ideia de convergência cis-heteronormativa entre sexo-gênero-desejo (BUTLER, 1990/2007), que dá sustentação ao determinismo biológico. Põem em xeque, ademais, uma perspectiva voluntarista: toda e qualquer performance de gênero é balizada por um "marco regulatório altamente rígido" (BUTLER, 1990/2007, p. 98). Performances de gênero são socialmente constrangidas, não dependem unicamente da vontade do sujeito. O constrangimento se dá pela via social, não pela biológica.

O filme, diferentemente de Gabriel, inclina-se mais ao questionamento do que à afirmação da existência de uma suposta essência, de um impositivo biológico-binário generificante. Não é apenas a ambiguidade moral dos personagens, destacada por Gabriel, que o filme explicita. Há performances de gênero e sexualidade que se mostram igualmente ambíguas: caberia considerar, além das performances de Vicente/Vera, as do próprio doutor (envolto em uma escala de desejo transerótico-afetiva) e, dentre outras, as de Norma (envolta por uma aura infantil, sua sexualidade aponta para uma escala temporal diferente da que corresponderia a uma mulher de sua idade). Gabriel, entretanto, não se detém a analisar o quão ambíguas chegam a ser tais performances, apenas comenta que a performance de masculinidade hegemônica de Vicente é posta em dúvida na narrativa fílmica ${ }^{20}$ por ele não ser visto como 'machão'. Eis aí outro exemplo, além dos já mencionados na análise, que ilustra o perigo de se naturalizar escalas, de se submeter performances de gênero a um "marco regulatório altamente rígido" (BUTLER, 1990/2007, p. 98).

19 Entendemos que a feminilidade, a masculinidade e a transgeneridade são sempre estrategicamente performadas.

${ }^{20}$ Neste momento da vídeo-crítica, fora do excerto analisado, Gabriel diz que Cristina, atendente da loja da mãe de Vicente, desconfia da masculinidade deste porque "ele não é lá um cara machão". 
Esperamos, por fim, que este artigo possa ter indicado o quão importante resulta romper com projeções que se espraiam de forma precisa e delimitada (TSING, 2015), que acabam por iconizar sujeitos e as performances que desempenham, apagando matizes destes/destas, levando-os a operar em meio a constrangimentos dicotômicos, ou seja, em meio a dinâmicas de recursividade fractal (IRVINE; GAL, 2000). Confiamos ter logrado sinalizar a relevância de dirigir nossa atenção para a produção de diferença em meio à repetição, conseguindo, desse modo, ir além da superficialidade ao 'perspectivizar perspectivas' sobre a forma como outras peles podem ser habitadas.

\section{REFERÊNCIAS}

ALONSO, S. L.; FUKS, M. P. Histeria. São Paulo: Casa do psicólogo, 2004.

AUSTIN, J. L. Quando dizer é fazer. Palavras e Ação. Porto Alegre: Artes Médicas, 1962/1990.

BADINTER, E. ¿Existe el instinto maternal? Historia del amor maternal. siglos XVII al XX. Barcelona: Ediciones Paidós, 1980/1991.

BAKHTIN, M. Estética da criação verbal. São Paulo: Martins Fontes, 1953-1954/2003.

BLOMMAERT, J. Discourse. Key topics in Sociolinguistics. Cambridge: CUP, 2005.

BUTLER, J. El género en disputa: el feminismo y la subversión de la identidade. Barcelona: Paidós, 1990/2007.

CARR, E. S.; LEMPERT, M. Scale: discourse and dimensions of social life. Oakland: University of California Press, 2016.

CASTELLS, M. A galáxia da Internet: reflexões sobre a internet, os negócios e a sociedade. Rio de Janeiro: Jorge Zahar, 2003.

DELEUZE, G. Cinema 1: a imagem-movimento. São Paulo: Brasiliense, 1985.

DELEUZE, G. Lógica do sentido. São Paulo: Perspectiva, 1969/1975.

DELEUZE, G. Michel Foucault, filósofo. Barcelona: Gedisa, 1990.

DERRIDA, J. Margens da filosofia. Campinas-SP: Papirus Editora, 1972/1991.

DERRIDA, J. Gramatologia. São Paulo: Perspectiva, 1973.

FOUCAULT, M. La historia de la sexualidad I. La voluntad de saber. México D. F.: Siglo XXI, 1976/1998.

FOUCAULT, M. Microfisica do poder. Rio de Janeiro: Graal 1972/1984.

FOUCAULT, M. O nascimento da clínica. Rio de Janeiro, Forense-Universitária, 1963/1980.

FOUCAULT, M. O sujeito e o poder. In: DREYFUS, H.; RABINOW, P. Michel Foucault, uma trajetória filosófica. Rio de Janeiro: Forense, 1982/1995.

GABRIEL, M. Marketing na era digital. São Paulo: Novatec, 2010.

GAL, S. Scale-making: comparison and perspective ideological projects. In: CARR, E. S.; LEMPERT, M. Scale: discourse and dimensions of social life. Oakland: University of California Press, 2016.

GAUDREAULT, A.; JOST, F. A narrativa cinematográfica. Brasília: Editora da UNB, 2005/2009.

GONZALEZ, C.; MOITA LOPES, L. P. Posicionamentos interacionais mobilizados por 'Tudo sobre minha mãe' na rede social Filmow. DELTA, v. 31, n. 2, p. 473-503, 2015.

GONZALEZ, C.; MOITA LOPES, L. P. Performance narrativa multimodal de Agrado em Tudo sobre minha mãe: desarticulando a autenticidade de gênero. RBLA, Belo Horizonte, v. 16, n. 4, p. 679-708, 2016.

GONZALEZ, C.; MOITA LOPES, L. P. Reflexividade metapragmática sobre o cinema de Almodóvar numa interação online: indexicalidade, escalas e entextualização. Trab. Ling. Aplic., Campinas, n(57.2): 1102-1136, maio/ago. 2018.

GUMPERZ, J. Contextualization and understanding. In: DURANTI, A.; GOODWIN, C. (Eds.). Rethinking context: language as an interactive phenomenon. Cambridge: CUP, 1992. p. 229-252. 
IRVINE, J. T.; GAL, S. Language ideology and linguistic differentiation. In: KROSKRITY, P. (Org.). Regimes of language. Ideologies, politics and identities. Santa Fe: School of American Research Press, 2000. p. 35-83. MOITA LOPES, L. P. Por uma Linguistica Aplicada Indisciplinar. São Paulo: Parábola, 2006/2016.

MOITA LOPES, L. P. O português no século XXI: Cenário geopolítico e sociolinguístico. São Paulo: Parábola, 2013.

PINTO, J. P. Prefigurações identitárias e hierarquias linguísticas na invenção do português. In: MOITA LOPES, L. P. (Org.). Português no século XXI: ideologias linguísticas. São Paulo: Parábola Editorial, 2013, p. $120-143$.

QUEIROZ, P. O corpo trans e o cinema: uma análise das obras de Almodóvar. In: SEMINÁRIO DE PESQUISA E PRÁTICA PEDAGÓGICA. 11., Vila Velha (ES), 2017. Anais do... Vila Velha: Praia Editora, 2017.

RECUERO, R. Redes Sociais na Internet. Porto Alegre: Sulina, 2009.

ROSE, D. Análise de imagens em movimento. In: BAUER, M. W.; GASKELL, G. (Eds.). Pesquisa qualitativa com texto, imagem e som: manual prático. Petrópolis: Vozes, 2002. p. 343-364.

SILVERSTEIN, M. Indexical order and the dialectics of sociolinguistic life. Language \& Communication, 23, p. 193-229, 2003.

TOFFLER, A. A terceira onda. Rio de Janeiro: Record, 1980.

TSING, A. The Mushroom at the End of the World: On the Possibility of Life in the Capitalist Ruins. Princeton/Oxford: Princeton University Press, 2015.

VELOSO, M. T. O sujeito do desejo na trama do discurso. Frederico Westphalen: URI FredericoWestph, 2012.

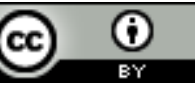

Este texto está licenciado com uma Licença Creative Commons Atribuição 4.0 Internacional. 